\title{
The optimal strategy for proximal mesh fixation during laparoscopic ventral rectopexy for rectal prolapse: an ex vivo study
}

\author{
Robin M. F. van der Weiden
}

Received: 1 February 2013/Accepted: 26 February 2013/Published online: 19 March 2013

(C) Springer Science+Business Media New York 2013

Formijne Jonkers et al. [1] concluded that the Karl Storz screw offers fixation strength similar to that of tacks for proximal fixation of mesh to cortical bone during laparoscopic ventral rectopexy. Laparoscopic bone anchor placement for mesh fixation in sacrocolpopexy procedures was developed in our hospital using a new laparoscopic device [2, 3]. Together with Karl Storz, a European patent was obtained [4]. We intend to use bone anchor fixation in robotically assisted laparoscopic sacrocolpopexy in the near future.

Disclosure Robin M. F. van der Weiden developed the laparoscopic instrument for bone anchor insertion and is the European patent holder together with Karl Storz, GmbH, Tuttlingen, Germany.

\section{References}

1. Formijne Jonkers HA, van de Haar HJ, Draaisma WA, Heggelman BGF, Consten ECJ, Broeders IAMJ (2012) The optimal strategy for proximal mesh fixation during laparoscopic ventral rectopexy for rectal prolapse: an ex vivo study. Surg Endosc 26:2208-2212

2. Van der Weiden RMF, Withagen MIJ, Bergkamp ABM, Mannaerts GHH (2005) A new device for bone anchor fixation in laparoscopic sacrocolpopexy: the Franciscan bone anchor inserter. Surg Endosc 19:594-597

3. Withagen MI, Vierhout ME, Mannaerts GH, Van der Weiden RM (2012) Laparoscopic sacrocolpopexy with bone anchor insertion: short-term anatomic and functional results. Int Urogynecol J 23:481-486

4. Van der Weiden RMF, Karl Storz GmbH \& Co (2011) KG 78532 Tuttlingen (DE). European Patent Specification: Assembly for attaching particularly a vagina to a spine. European Patent Office Bulletin 2011/11 (EP 1718215B1), 16 Mar 2011 